\title{
How to Further Promote Community Fire Control Work
}

\author{
Zhang Qian ${ }^{1}$ \\ (1. The Ministry of Scientific Research, Training Department, Public Security Fire Brigade Junior \\ College, Kunming, Yunnan Province 650208)
}

Keywords: Community Fire Control, Further Promotion, Status Quo, Measures

\begin{abstract}
Via analysis on the status quo of community fire control work, particularly on how community fire control work does not match current development, the paper proposes concrete measures on how to further promote community fire control work, in a hope to offer certain reference for the further development of community fire control work.
\end{abstract}

\section{Introduction}

Community is the basic cell of city. With further deepening of urbanization, community fire control work has become important component in city protection mechanism, and caught high attention of all levels of leaders and the public. Community fire control work is confronted with huge challenges. At the face of new opportunities and challenges, the author integrates regional status quo, stands on present and long-term construction point of view, bases on detailed analysis on the incompatibility of community fire control work and current development, and proposes concrete measures for resolution.

\section{Community Fire Control Work Status Quo}

2.1 All level personnel may not have sufficient focus, attention, and protection awareness on community fire control work.

For this region, community fire control work mainly relates personnel including: personnel at street (town) comprehensive affairs offices; resident committee cadres; community residents.

2.1.1 Personnel at street (town) comprehensive affairs office do not endeavor sufficient attention to community fire control work.

Attention is placed upon "hardware configuration", while neglect is placed upon "software construction". In hardware construction, attention is thrown upon "one-time investment", while neglect is thrown upon "daily maintenance". Community fire control work is often just for "point", instead of "plane". It is hard to rationally plan community fire control work as a whole.

2.1.2 Residents committee cadres do not have sufficient attention to community fire control work.

Given that workload is heavy and the number of personnel is comparatively small, this level of personnel does not have the time to take care of community fire control work. The conduction process is sustained at a steady presence.

2.1.3 Some of the community residents lack fire safety precaution.

This is mainly represented by: first, leasees generally are in lack of the ability to prevent fire, extinguish fire, and escape from fire. Once their minds are dumb, or when they are not careful with fire or electricity, disaster is prone to occur. Second, vulnerable groups, e.g. old people who live alone, children, and the disabled, may not deal with fire disaster properly or get injured or die as they are not convenient in taking actions, and their intelligence are limited. Third, as home decorations are not in line, "congenital” hidden danger could have been embedded, and become major killer to induce fire.

2.2 Various types of mechanism for community fire control work have not formed consecutive, interactive, orderly benign operation state.

With support from government at all levels, and the concerted efforts of relevant departments, community fire control work is gradually setting up perfect mechanism, e.g. community fire control 
work network mechanism, community fire control propaganda work mechanism, which pave solid foundation for leap development of community fire control work. Nevertheless, from the view of present operation, mechanisms are still staging on papers and walls. There lacks "tension" and "vitality". No "continuity", "interaction" and "orderliness" have been shaped. First, residents committee does not often promote fire control. Some of the communities depend on administrative orders from superior meetings and notices to develop community fire control propaganda work. Second, horizontal interaction and aligned protection require enhancement in between departments. Departments such as community, real estate, and property owners' committee, are the main bodies to carry out community fire control work. As districts are different from one and another, accounts outstanding are long-pending, and supervision mechanism is not perfect, situations such as pushing balls to one and another, acting for its own interest, and inability to get funds do occur in carrying out community fire control work. Third, some of the mechanisms are in disorder, e.g. old communities hire elderly people for fire control work at low cost due to financial difficulties. These elderly people are not good at body fitness and literacy quality. They are not able to shoulder the important responsibility for safety such as maintaining order and fire control. As well, for new communities, most of the efforts are devoted to how to ensure order. Hardware construction for community fire control is paid attention to while neglecting software construction such as developing fire control safety training.

2.3 In horizontal comparison, the development of community fire control work is imbalanced and inharmonious.

From the perspective of annual fire control work special fund budgeting condition, the annual budget of the regional level is uneven. The gap is huge, as the lowest reaching fifty to sixty thousands whole the highest reaching millions. This may have direct link to the economic condition of the region. Community fire control safety distribution discloses that work is largely concentrated on old residential regions with higher urbanization development level. Given the congenital deficiencies, building fire rating is low, and there are a number of potential fire risks. Communities at the conjunction of city and urban areas, possess many migrant workers, whose fire control awareness are low, and where fire control water resources are scarce, and wires are lined up in a haphazard fashion. From the time of community formation, communities with long history have strong awareness for fire control, and residents pay attention to and are passionate to participate community fire control work, and the atmosphere of promoting community fire control is comparatively dense; on the contrary, communities with short history do not have high participation of residents, and the promotion of fire control is not in place. Horizontal comparison facilitates integral planning, and balancing community fire control work, so as to improve integrated, comprehensive software and hardware power.

2.4 Community fire control legal construction is blank.

“People's Republic of China Law of Fire Control” implemented on May $1^{\text {st }}, 2009$, clearly defines that ${ }^{[1]}$ : resident committees should assist government and public security organ, in promoting and education of fire control. Residential property services companies must maintain and manage public fire control facilities in their management region, offer fire control safety services. Upon requirements, resident committees shall establish volunteer fire brigade and other multiple forms of fire control organizations, and develop resident self protection and self salvation work. These regulations, point out correct direction for community fire control work under new situation. However, community fire control work code and conducts in match with new "Law of Fire Control" have not been released at the moment. It is hard to start community fire control work by law. Currently, the advance of regional community fire control work mainly depends on administrative instructions and documents, notifications issued by local government. Such administrative instructions and documents, notifications are then carried out by regions on their own. This kind of management mode lacks integral constraints on community fire control work, and cannot guarantee the long-term effects of various fire control mechanisms. "Inconstant" situations are very likely to happen, which are not beneficial to the long-term development of community fire control work. 


\section{Concrete measures to further promote community fire control work}

3.1 Focus on key elements, continuously promote legal process of community fire control work Community fire control work must always adhere to "Law of Fire Control", closely rely on the unified leadership of local government, fully bring into play the assistance of fire departments, timely submit plans, suggestions or comments on how to strengthen community fire control work, continuously promote legal process of community fire control work. During the process of promoting Law of Fire Control, the five key elements must be grasped and fixed in legal form. First, determine the main responsibilities and post requirements of leader departments, supervision departments, community management units, owner committee, and property management in community fire control work. Second, clarify various guarantee terms in fund raising, investment, and use in community fire control work. Third, define concrete requirements of all mechanism operations. Fourth, specify community fire control work in comprehensive management and the construction of community safety, implement one-vote veto for ineffective community fire control work that lead to frequent fire disaster or more than three persons of casualties. Fifth, explicitly set community fire control work organization, personnel, activities and requirements.

3.2 Adopt effective measures to ensure perfect, and effective operation of various mechanisms in community fire control work

To ensure good and effective operation of community fire control work, the author considers: first, all mechanisms must be fixed in legal form, to prevent artificially adding and deletion which may result in "empty talk" in implementation. Second, take administrative means as auxiliary assistance, form a set of incentives and disincentives of community fire control work, conduct comprehensive quantitative assessment on the implementation of responsibilities, encourage the advanced, and spur the lagging behind. Third, adapt to trend, perfect mechanism. The new round of five year community compliance assessment mechanism is of great practical significance to promoting community fire control work. It takes pilot community as lead, and build communities with "Seven One" mode, namely, one fire distinguish equipment location, one resident fire prevention convention, one fire control promotion bulletin, one fire control education room, one fire emergency plan, one fire control promotion activity on the $9^{\text {th }}$ of each month, one work duty.

3.3 Stand on resolving difficult issues, and constantly vertical and deeper development of community fire control work

In promoting community fire control work, there are three difficulties worthy of our attention. First, pay attention to the mentally retarded, the mentally handicapped, children, elderly people living alone, and other vulnerable groups who have "congenital" weakening issues for fire safety awareness and capability. Second, pay attention to lack of interaction and attraction in the promotion of community fire control work. Third, pay attention to blind spot in community fire control work.

For the first issue, in the author's opinion, linkage with education system must be strengthened. Implement primary and secondary school students fire safety training by phase, step by step, and in gradual model, to ensure that every student is educated, and accomplish the goal of "one person" drives "the whole family". In addition, periodically organize "one-on-one" help by fire control volunteer for the mentally retarded, the mentally handicapped children, elderly people living alone, and other vulnerable groups. Remind them of fire safety and conduct daily safety supervision, in order to reduce the incidence of tragedy brought by fire. Furthermore, step by step, one by one, organize community fire emergency evacuation drills, so that those vulnerable groups can improve the ability in emergency evacuation escape via experience in person.

For the second and third issues, the author believes, "monthly performance" work group must be established to promote fire control to start with. Cycle performance is to be put on show on monthly basis to introduce fire control into the daily life of people. At the same time of attracting interactions from residents, enhance their fire control knowledge in a subtle way. Besides, in accordance with the idea of "full coverage of fire control experience", formulate scientific blueprint for community fire control work, adopt incentives or rewards to mobilize each family to have "in person" experience in the nearest fire station and fire museum, and solidly improve the level of knowledge 
and the fire escape self-help capabilities. Last but not least, rely on community police for routine fire prevention and fire safety regulatory responsibilities; depend on community fire service teams for utilization of resources for fire control promotion; count on community fire safety inspections teams for 24-hours round visit and fire safety reminder; and have confidence in voluntary community fire brigade for initial discovery of fire, alarm and pre-disposition.

\section{Conclusion}

As the era is developing, and the economy is uplifting, community fire control work will be faced with new situations and new issues. However, as long as we keep pace with the time, carefully study and pay attention to current trends, focus on resolving the difficult and heated issues, community fire control work will be evolved in the hearts of all residents, develop and grow, and create a better future for the well-being of community residents.

\section{Reference}

[1] People's Republic of China Law of Fire Control. The 5th Session of Standing Committee of the 11th National People's Congress. [Z].2009

[2] The ministry of public security,Etc. To strengthen the city community fire control work. [Z]. 2005

[3] Gao Feng,Liu Yang. Some thoughts on strengthening community fire management work. Security. [J]. 2010(6):45

[4] Wang Tieshi. To strengthen community fire control work. Economic and technological cooperation information. [J]. 2010(24):107 